\title{
Antimicrobial peptides, novel solution for the treatment of precancerous disease acne - A review
}

\author{
Diana M Gómez ${ }^{1,2 *}$, Yu-Chun Lone ${ }^{2,3}$, Luz M Salazar ${ }^{1}$ and Jerzy Trojan ${ }^{2,4 *}$ \\ ${ }^{1}$ Faculty of Sciences, Dept. Chemistry, Univ. Nacional, Bogota, Colombia \\ ${ }^{2}$ ICGT - Bogota/Paris, Colombia \\ ${ }^{3}$ INSERM, UMR 1197, Cancer Center, Villejuif, France \\ ${ }^{4}$ INSERM, U 602, Cancer Center, Villejuif, France
}

\begin{abstract}
Acne is one of the most common epithelial diseases affecting approximately $80 \%$ of the world's population between the ages of 16 and 35 . It is caused by multiple factors such as genetic predisposition and hormonal alteration including growth factor IGF-I, among others.

Acne being related to IGF-I expression, is involved in possible apparition of malignant diseases. The pathology of acne is limited to the pilosebaceous unit. The evolution is governed by the increase in colonization of the bacteria Propionibacterium acnes (P. acnes). Acne is clinically manifested by the appearance of comedones with a tendency to inflammation. Finally causes scarring damaging self-esteem and quality of life of those who suffer it. As proposed therapies, external treatments have been developed such as inhibitors of IGF-I among others. As an internal treatment, the innate response of the patient's immune system to the presence of an invading microorganism has been studied, highlighting anti-microbial peptides as the host's own defense molecules. This work shows a compilation of the most relevant and current antimicrobial peptides that could be used as potential therapeutic agents against microorganisms located in the skin and related to acne disease.
\end{abstract}

\section{Introduction}

Acne also known as acne vulgaris (acne vulgaris) is a disease that affects the skin. It is caused by multiple factors such as genetic predisposition, hormonal alteration, stress levels, skin irritation, response to medications, among others. This disease is limited to the pilosebaceous unit (hair follicle and sebaceous glands) where it acquires different degrees of severity, is clinically manifested by the appearance of comedones with a tendency to inflammation and finally cause scarring damaging self-esteem and quality of life of those who suffer it. The evolution is governed by the increase in sebum production, hyperkeratinization, follicular obstruction and increase in colonization of the bacteria Propionibacterium acnes (P. acnes), present in the skin microbiota [1].

In order to control this disease, external treatments have been developed that reduce symptoms such as bacteriostatic topicals, hormonal medications, inhibitors of insulin growth factor-I (related to cancer development) [2], pro-inflammatory blockers, among others.

Acne focuses on chronic inflammation of pores or pilosebaceous units composed of keratinocyte cells, sebaceous glands and hair follicles, these holes are lubricated by the substance produced by the sebaceous gland called sebum, which also functions as a carrier of dead epithelial cells to the surface following the follicular canal [3]. When there is: an increase in the production of dead cells, the impediment in the normal flow of sebum and the obstruction by the hair in the exit of the pore, a plug is formed, in which the bacteria present in the microbiota of the skin invade the abscess and cause swelling. For this reason, the most relevant factors of pathogenesis are: abnormal hyperkeratinization, increased sebum secretion and inflammation of the pore due to the exaggerated presence of microbial flora $[1,4]$.

The majority of the grains are distributed in the upper area of the trunk being the face the most affected place, the consequences can be both physical and psychological impacting finally in the psychosocial environment of the patient [5]. According to the World Health Organization, $80 \%$ of the population between 15 and 35 years of age will suffer epithelial alteration at some point in their lives, bearing in mind that the prevalence of these lesions decreases with age [6-8].

\section{Physiopathology of acne}

The lesion begins with the increase in sebum secretion by the sebaceous gland which the pore is unable to support, this fact alters the cycle of epithelial desquamation accumulating dead keratin cells at the top of the follicular canal, leading to the formation of comedones or fat plugs that prevent the normal evacuation of fluid [9]. Comedones can close when dead corneocytes, sebum and microbial flora are trapped within a blocked pore, and the pressure of the retained mass creates a white papule that can cause internal rupture of epithelial tissue invading

${ }^{\star}$ Correspondence to: D.M. Gomez, Faculty of Sciences, Dept. Chemistry, Univ. Nacional, Bogotá D.C., Colombia, E-mail: dimgomezmo@unal.edu.co

J. Trojan, ICGT, Cll 128 b, Kr 18-11, Bogotá D.C., Colombia, E-mail: genetherapy@hotmail.fr

Key words: acne, Propionibacterium acnes, anti-microbial peptides, cancer, IGF-I

Received: October 25, 2019; Accepted: November 14, 2019; Published: November 18, 2019 
the dermis and causing internal inflammation. The open comedón is a corneal plug that is shown with a visible hole of black tonality whose color is conferred by the mixture between melanin and oxidized fat, if the cyst bursts it can interact with the bacterial microorganisms that surround the pore as the P. acnes, which favors the inflammation and evolution to pustula or papule $[10,11]$.

At the same time, the accumulation of this mass in the pilosebaceous unit generates an ideal environment for the propagation of microorganisms that are normally found in the skin microbiota such as Propionibacterium acnes [12]. The result is redness or swelling, because an immediate response is triggered in the host's innate immune system by detecting the presence of $\mathrm{P}$ bacteria. acnes in the sebocite generating an infection process, which is capable of activating the classic pathways of the immune system through immediate response cells such as neutrophils, macrophages and keratinocytes that recognize the presence of an invading microorganism by means of Toll type receptors (TLRs -2 and -4 ), which induce the production of pro-inflammatory cells such as interluquins (IL - $6,-8,-12$ ) gamma interferon (IFN- $\gamma$ ) and tumour necrosis factor alpha (FNT- $\alpha$ ) which contribute to tissue damage and local inflammation $[13,14]$.

Likewise, the mechanism can stimulate the production of complementary molecules of the immune system with antimicrobial activity, such as the Beta-Human Defensin peptide whose expression is derived from the skin inflamed by infection and contributes to interact electrostatically with the membrane of the invading microorganism generating a pore that causes an osmotic imbalance, these inflammatory responses physically generate the formation of nodules or cysts that in many occasions leave the scar on the patient (Figure 1) $[4,15,16]$.

\section{Treatments}

Various treatments have been proposed to counteract the factors mentioned above that cause acne. The most commonly used anti-acne agents are the non-pharmacological ones, which include skin cleansers, water-based lotions, among others, which can act as a disease attenuator. On the other hand, the procedures with drugs are specified according to the severity and the zone in which the dermopathy is located, they can be topical, antibiotics and systemic, such as retinoids, tetracyclines and estrogen contraceptives respectively. However, adverse effects such as skin irritation, dryness, erythema, photosensitivity, etc., vary depending on the dose used. The controversy arises when studies show the resistance and tolerance of bacteria to the frequent use of these drugs, although these therapies are still used to treat acne, safer and more efficient agents need to be used [17]. Recently it has been proposed to study the defense mechanism of the host immune system, which highlights the activity of antimicrobial peptides as defense complements in the presence of an invading microorganism showing promising results as possible candidates for acne treatment [18].

\section{Antimicrobial peptides}

Antimicrobial peptides are molecules containing residues of amino acids covalently bonded through an amide bond (generally less than $8 \mathrm{KDa}$, although there is longer length) $[19,20]$ are widely distributed in all kingdoms of nature, their main function is to complement the response of the innate immune system to the presence of any pathogenic microorganism [21]. They constitute essentially conserved components of the host's defense line against infections coming from invaders such as: bacteria, fungi, parasites and viruses, they present diverse roles to lysar or inhibit the growth of the microorganism and/ or favor processes; inflammatory, chemothactic, angiogenic, they also favor cell proliferation, phagocytosis, repair of tissue damage, induce the release of cytokines, among others [22].

Peptide-pathogen interaction has recently been studied in the Canadian research group of Dr. Hancock et al. where the viable use of these biomolecules has been demonstrated in comparison with classical antibiotics [23-25], awakening the interest of the pharmaceutical industry to use antimicrobial peptides as potential therapeutic agents, as it has shown the ability to reduce side effects that other conventional synthetic molecules usually cause [26].

Of the databases that at the moment are more complete in Antimicrobial Peptides are; APD3 (Antimicrobial Peptide Database 3)

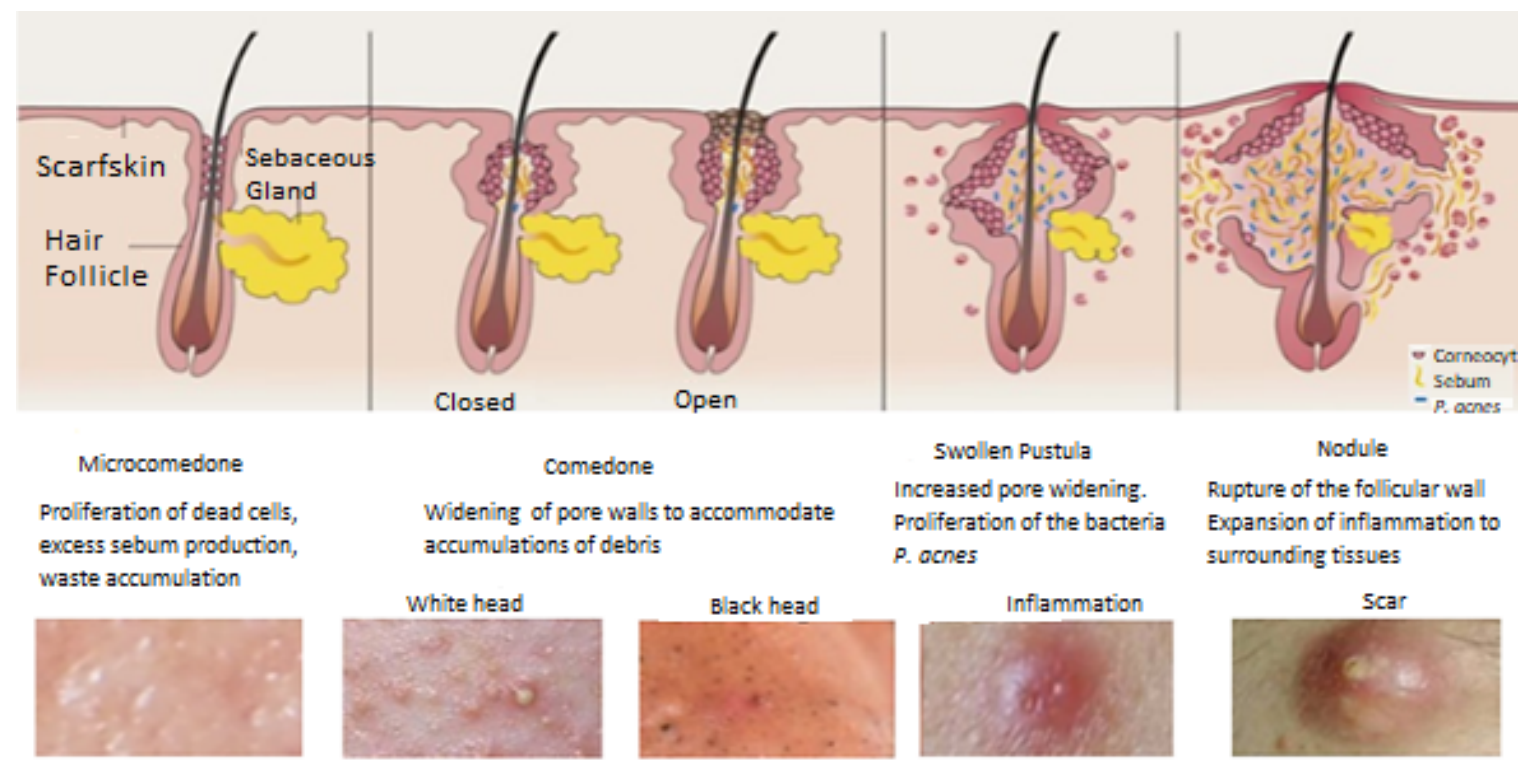

Figure 1. Acne stages. Adapted from [16]. 
y CAMPR3, (Collection of Anti-Microbial Peptides), which report more than 2500 identified and classified antimicrobial peptides that provide up-to-date information on these biomolecules [27,28].

Classification of antimicrobial peptides: The diversity of antimicrobial peptides in terms of sequence, structure and function continues to expand, therefore their classification continues to be updated on a daily basis [29]. However, the classification is based on: biological source, sequence characteristics, structural conformation, biological target and molecular target [25]. Further information is mentioned below:

Biological source: The classification proposed by R. Whittaker has been adopted, which is based on the five natural kingdoms; prokaryotes (bacteriocines), protists (algae/archaeas), fungi, plants and animals, this classification is the first form of discrimination in the databases $[28,30]$.

Characteristics of the sequence: Antimicrobial peptides can be classified by their sequence characteristics such as:

Load: peptides can be classified as cationic, anionic or neutral at physiological $\mathrm{pH}$ depending on their amino acid composition. They are generally positively charged (+3) to favour electrostatic interactions with the negatively charged lipid bilayer [31-33].

Length: The size of antimicrobial peptides ranges from $300 \mathrm{Da}$. to 8 $\mathrm{KDa}$ (from 3 to 75 residues) approximately. The majority of the peptide population is in the approximate range of $21-30$ amino acids ( $₫ 80 \%)$ $[33,34]$, the length of the antimicrobial peptide has been reported to influence the ability to cross the membrane [35].

Hydrophobicity: This property ranges from $40-50 \%$ in most peptides, allows to determine how soluble is the molecule of interest, based on the interaction of the lateral chain of amino acids with the aqueous medium [36].

Amphipaticity: a property of the molecule that refers to the relative abundance of residues or hydrophilic and hydrophobic regions in the same sequence [37].

Structural conformation: According to the intrinsic properties mentioned above and the diversity of sequences reported, this group organizes the antimicrobial peptides according to the similarity of the tertiary structure, categorizing them into four large groups according to Van't Hof et al. [24,38]: alpha - helical, folded leaf beta, combination between alpha - beta and in extended conformation or without defined structure (ramdom coil) [39,40].

Biological target: The antimicrobial peptide of natural origin usually has a wide spectrum of biological activities such as antibacterial, antiparasitic, antifungal, antiviral, among others, depending on the microorganism with which it comes into contact: bacteria, parasite, fungus or virus, respectively $[27,41,42]$.

Molecular target: This classification is based on the type of target or target reached by the peptide once in contact with the microorganism, usually categorized into two types: those that interact with the membrane and distort it, and others that present activity only if they cross the membrane [43]. Once inside, the antimicrobial peptides are directed to different organs of the cell, such as the ribosome or the nucleus among others, affecting its functions, inhibiting metabolic processes and finally leading to the death of the invader [44].

\section{Mechanism of action of antimicrobial peptides}

The ability of some antimicrobial peptides to exert their bactericidal action usually depends on their ability to interact with the membrane or cell wall and/or internal targets such as the nucleus (DNA synthesis), or ribosome (protein synthesis), among other organelles [45]. The way they interact with peptide-pathogen is the key to understanding their mode of action and the properties mentioned above determine that interaction [46].

Several techniques have been used to evaluate the mechanisms by which the antimicrobial peptide contacts the microorganism and exerts its action. However, each method provides a slightly different view of peptide activity and no individual technique has been able to determine with certainty the mechanism of action of the peptides [47]. Several models are proposed to explain the probable interaction, a proposed model of action is the formation of the pore "barrel type" which postulates a cylindrical pore coated with peptide in which the hydrophobic face of the peptides interact directly with the acyl chains in the phospholipid nucleus while the hydrophilic side of the peptides is oriented towards the interior of the pore [48]. The other probable model that allows the membrane to be altered by means of channels is the "toroidal type" whose name refers to generating a closed curvature when rotating around an axis, that is, there is an integration between the antimicrobial peptides and the lipid chains, where the hydrophilic regions of the peptide face the inside of the pore and the hydrophobic regions remain in contact with the phospholipid, forcing a curvature in the bi-layer, promoting the union between the external and internal membrane $[49,50]$.

There is another possible mechanism that explains the translocation of the membrane once there is peptide-pathogenic contact, the "carpet-type" model is used to describe the capacity of aggregation of the peptides on the membrane and generate tension, as a detergent promoting the formation of micelles [51,52]. Peptidemembrane electrostatic attraction covers the surface of the host at different sites as a carpet (Figure 2) [53].

\section{How to obtain antimicrobial peptides}

The synthesis and obtaining of therapeutic products based on peptides was from its beginnings a costly and inefficient technique which diminished its development and production. The proposed synthesis method depends on many variables, such as purity, solubility, yield, stability, delivery mechanisms and dose administration, in addition to evaluating other criteria such as modifications in the lateral chains and incorporation of non-natural molecules, among others. However, the panorama changed, it is currently reported that the synthesis of a peptide drug proposed as an alternative to conventional drugs, could generate a favorable cost benefit for the industry and its subsequent consumer $[54,55]$. The production of peptides is mainly based on three different ways: biological synthesis consisting of the production of peptides in the ribosome by genetic coding [56], recombinant synthesis considers a deoxyribonucleic acid plasmid encoding a peptide of interest is introduced into a vector that will act as a storage complex and subsequent expression of information $[57,58]$ and the chemical synthesis in solid phase that consists in elongating the peptide chain from $\mathrm{C}$ to $\mathrm{N}$-terminal on a functionalized and insoluble matrix, by means of the successive coupling of strategically protected amino acids which compose the sequence [59]; the reaction is given by the formation of an amide bond (peptide bond) between the carboxyl functional group of the incoming amino acid and alpha amino of the amino acid previously coupled, thus, the synthesis methodology allows cyclic processes of coupling, un-protection and subsequent separation of the solid support facilitating the elimination of reaction intermediates 


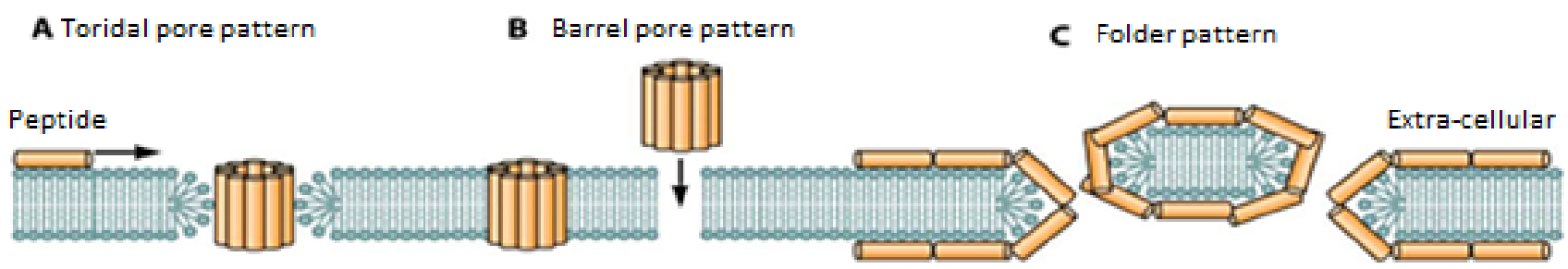

Figure 2. Models of interaction of the peptide on the membrane of the microorganism. Adapted from [48]

and by-products by means of filtration and washing which facilitates the construction of this type of molecules [19].

\section{Proposed anti-microbial peptides}

In recent years antimicrobial peptides (AMPs) have been considered promising molecules in the defense of the host for their functions as antibacterial agents taking into account: the diversity in possible mechanisms of action, the relative affinity according to the properties of the peptide towards microbial membranes, the broad spectrum of antimicrobial interaction and especially the low resistance to bacterial strains [60]. These are some of the PAMs, most studied with bactericidal characteristics against $P$. acnes:

Defensins, one of the most widely studied molecules and characterized by keratinocyte cells, play a very important role in the innate immune system, especially in the skin and liver. They are cationic sequences, rich in cysteines, which enable them to form disulfide bridges and stabilize themselves by the conformation they generally adopt of the beta-leaf type [61], studies show that these molecules interact with the microorganism through electrostatic interactions with the lipid membrane of the host generating pores possibly folder model, promoting the death of the microbe by osmotic imbalance [62]. Human beta-defensin type 2 (hBD-2) has been identified as a pro-inflammatory molecule in psoriasis and acne lesions activated by the presence of $\mathrm{P}$. acnes bacteria [63].

Human cathelicidine is a cationic peptide composed of 37 amino acids with amphipathic regions and an alpha-helicoidal tendency. It is expressed by different epithelial cells such as keratinocytes, mast cells, neutrophils, among others [64]. It interacts initially by electrostatic action with the membrane of the P. acnes and it has been demonstrated that due to its tertiary structure it is capable of being inserted in the lipidic bi-layer promoting the formation of pores-channel that allow the entrance and exit of cellular material, concluding in the death of the pathogen $[42,65]$.

Granulisine, a high molecular weight peptide found in natural killer cells (NK) and cytotoxic T cells, has a broad bactericidal spectrum in which $\mathrm{P}$. acnes is included, has 5 alpha helicoidal regions in the tertiary structure, is made up of 74 amino acids of which two disulfide bonds are contained [66]. This polypeptide has presented alternatives for the treatment of the disease, the most relevant fragment contains the residues of $31-50$ of the sequence with antibacterial and antiinflammatory effects especially when it is synthesized with modified D-amino acids. Its bactericidal activity lies in the innate capacity of the molecule to be toxic in the presence of foreign bodies such as P. acnes, which inhibits its growth and proliferation in the presence of the peptide [67].

The LZ1 peptide synthesized by Zhang and collaborators comes from the fusion of recognized families of antimicrobial peptides, these fusion compiles the "optimal" length, load, hydrophobicity and amphipaticity of a molecule with antibacterial activity, the result was a monomer of 15 residues with helical alpha tendency and amphipathic properties. It was developed to act as an inhibitor in the growth of $\mathrm{P}$. acnes and Staphylococcus epidermis bacteria, it also presents antiinflammatory activity because it prevents the secretion of cytokines, improving the results obtained by the native sequences of each original family [68].

The CEN1HC-Br antimicrobial peptide studied by the group of Cheng et al. was isolated from the green sea urchin, comes from the Centrocin1 peptide (CEN1HC) a heterodimeric peptide of 30 amino acids with an intramolecular disulfide bridge, the essence of the CEN1HC-Br peptide is found in the presence of the halogenated atom, which attributes antimicrobial activity against the bacterium Propionibacterium acnes with lower concentration per dose administered (in vivo) compared to a conventional drug such as Climdamicin ${ }^{\star}$ or Eritromicin ${ }^{\star}$ used for the treatment of acne and with possible anti-inflammatory effects, however continues to be studied because the presence of bromine may generate side effects in the medium to long term in a possible treatment in humans [69].

\section{Discussion}

The problem of acne is caused by the resistance and tolerance of Propionibacterium acnes bacteria to conventional drugs, evidenced by the dermatological damage suffered by the patient $[1,3,4]$. For this reason, antimicrobial peptides emerge as a novel therapeutic option for treatment and possible eradication.

Research has already begun on the subject with some of the peptides described above and there is a great possibility of additional research combined with other techniques such as bioinformatics or rational design to generate new molecules with possible greater antibacterial activity.

As proposed therapies, external treatments have been developed such as inhibitors of insulin growth factor IGF-I. In numerous previously published papers concerning the treatment of malignant diseases expressing IGF-I, we have underlined two things. IGF-I is not only the precancerous marker $[70,71]$. The therapy of different diseases and especially malignant diseases, using the inhibitors targeting IGF-I, especially IGF-I antisense technology, is the most efficient in current cancer treatment $[72,73]$.

Acne may be linked to increased risk of melanoma, breast cancer and prostate cancer [74-76]. The likely link involves Insulin-like Growth Factor-1 as a general stimulant, synergized by the steroid hormones [77-80]. Hormones that drive acne and breast cancer may also play a role in mole formation. As to acne in teenagers, they were 44 percent more likely to develop melanoma and also 17 percent more likely to develop breast cancer [74-76]. 
We think in the future to apply the gene therapy anti IGF-I, for acne treatment. The gene therapy anti IGF-I is also an immune gene therapy. The immune aspect of the treatment plays also a role in internal treatment of acne constituting the subject of the presented manuscript; as an internal treatment, the innate response of the patient's immune system to the presence of an invading microorganism has been studied, highlighting anti-microbial peptides as the host's own defense molecules. This work has showed a compilation of the most relevant and current antimicrobial peptides that could be used as potential therapeutic agents against microorganisms located in the skin and related to acne disease

\section{Authorship}

All authors have contributed equally to the writing of the manuscript and have approved the final version of the manuscript.

\section{Acknowledgement}

Special thanks to professors of Department of Chemistry, National University, Bogota, for their valuable guidance, teaching and collaboration in the development of this research.

\section{Funding information}

Subvention of Department of Chemistry, National University, Bogota,

\section{Competing interest}

No competing interest.

\section{References}

1. Fox L, Csongradi C, Aucamp M, du Plessis J, Gerber M (2016) Treatment modalities for acne. Molecules 21. [Crossref]

2. Trojan J, Shevelev A, Ly A, Pan YX, Guo Y, et al. (2019) Twenty-five years of cancer gene therapy: Anti-Gene IGF-I approach. Brit J Cancer Res 2: 325-333.

3. Li WH, Fassih A, Binner C, Parsa R, Southall MD (2018) Low-level red LED light inhibits hyperkeratinization and inflammation induced by unsaturated fatty acid in vitro model mimicking acne. Lasers Surg Med 50: 158-165.

4. Saint-Jean M, Dreno B (2016) Acné. EMC-Dermatología 50: 1-14.

5. Koreck A, Pivarcsi A, Dobozy A, Kemény L (2003) The role of innate immunity in the pathogenesis of acne. Dermatology 206: 96-105. [Crossref]

6. Tabri F, Patellongi I, Wahab S, Djawad K (2017) Analysis of nutritional status and levels of sebum on various age groups. Am J Clin Exp Med 5: 26-29.

7. Özçelik S, Kulaç İ, Yazıcı M, Öcal E (2018) Distribution of childhood skin diseases according to age and gender, a single institution experience. Turk Pediatr Ars 53: 105112.

8. Wolkenstein P, Machovcová A, Szepietowski JC, Tennstedt D, Veraldi S, et al. (2018) Acne prevalence and associations with lifestyle: a cross-sectional online survey of adolescents/young adults in 7 European countries. J Eur Acad Dermatology Venereol 32: 298-306.

9. Tahir CM (2016) Pathogenesis of acne vulgaris: simplified. J Pakistan Assoc Dermatology 20: 93-97.

10. Williams HC, Dellavalle RP, Garner S (2012) Acne vulgaris. Lancet 379: 361-372. [Crossref]

11. Marks JG, Miller JJ, Marks JG, Miller JJ (2019) 12-Pustules. In: Lookingbill and Marks' Principles of dermatology, pp: 166-183.

12. Luengo MTL (2011) Acné vulgar: abordaje fitoterapéutico. Offarm Farm y Soc 30: $48-52$.

13. Patel T, Patel S, França K, Keri J (2016) Acne and rosacea. In Stress and skin disorders: Basic and clinical aspects, pp: 149-153.

14. Dréno B (2017) What is new in the pathophysiology of acne, an overview. J Eur Acad Dermatol Venereol 31: 8-12. [Crossref]
15. Dréno B, Pécastaings S, Corvec S, Veraldi S, Khammari A, et al. (2018) Cutibacterium acnes (Propionibacterium acnes) and acne vulgaris: A brief look at the latest updates. Journal of the European Academy of Dermatology and Venereology 32: 5-14.

16. Ito K, Masaki S, Hamada M, Tokunaga T, Kokuba H, et al (2018) Efficacy and safety of the traditional Japanese medicine Keigairengyoto in the treatment of Acne Vulgaris. Dermatol Res Pract.

17. Zouboulis CC, Katsambas AD, Kligman AM (2014) Pathogenesis and treatment of Acne and Rosacea.

18. Cubana R, Tropical M (2009) Péptidos antimicrobianos: potencialidades terapéuticas Rev Cubana Med Trop 52: 2007-2010.

19. Guzmán F, Barberis S, Illanes A (2007) Peptide synthesis: Chemical or enzymatic Electronic Journal of Biotechnology 10: 279-314.

20. Cruz J, Ortiz C, Guzmán F, Fernández-Lafuente R, Torres R (2014) Antimicrobial peptides: Promising compounds against pathogenic microorganisms. Curr Med Chem 21: 20 .

21. Shai Y (2002) Mode of action of membrane active antimicrobial peptides. Biopolymers 66: $236-248$.

22. Travkova OG, Moehwald H, Brezesinski G (2017) The interaction of antimicrobial peptides with membranes. Advances in Colloid and Interface Science 247: 521-532.

23. Hancock RE, Scott MG (2000) The role of antimicrobial peptides in animal defenses. Proc Natl Acad Sci U S A 97: 8856-8861. [Crossref]

24. Jenssen H, Hamill P, Hancock REW (2006) Peptide antimicrobial agents. Clin Microbiol Rev 19: 491-511.

25. Mojsoska B, Jenssen H (2015) Peptides and peptidomimetics for antimicrobial drug design. Pharmaceuticals (Basel) 8: 366-415. [Crossref]

26. Moore A (2003) The big and small of drug discovery. Biotech versus pharma: Advantages and drawbacks in drug development. EMBO Rep 4: 114-117.

27. Wang G, Li X, Wang Z (2016) APD3: The antimicrobial peptide database as a tool for research and education. Nucleic Acids Res 44: D1087-D1093.

28. Waghu FH, Barai RS, Gurung P, Idicula-Thomas S (2016) CAMPR3: A database on sequences, structures and signatures of antimicrobial peptides. Nucleic Acids Res 44 : D1094-D1097.

29. Wang G (2015) Improved methods for classification, prediction, and design of antimicrobial peptides. Computational Peptidology 1268: 43-66.

30. Mahlapuu M, Håkansson J, Ringstad L, Björn C (2016) Antimicrobial Peptides: An emerging category of therapeutic agents. Front Cell Infect Microbiol 6.

31. Bobone S (2014) Peptide and protein interaction with membrane systems.

32. Zhou P, Huang J (2015) Computational peptidology.

33. Fan L, Sun J, Zhou M, Zhou J, Lao X, et al. (2016) DRAMP: a comprehensive data repository of antimicrobial peptides. Sci Rep 6: 24482. [Crossref]

34. GuangShun W (2010) Antimicrobial peptides: discovery, design and novel therapeutic strategies. Wallingford: CABI.

35. Gagnon MC, Strandberg E, Grau-Campistany A, Wadhwani P, Reichert J, et al. (2017) Influence of the length and charge on the activity of $\alpha$-helical amphipathic antimicrobial peptides. Biochemistry 56: 1680-1695.

36. Burns A, Olszowy P, Ciborowski P (2016) Biomolecules. In: Proteomic profiling and analytical chemistry Elsevier, pp: 7-24.

37. Kumar P, Kizhakkedathu JN, Straus SK (2018) Antimicrobial peptides: Diversity, mechanism of action and strategies to improve the activity and biocompatibility in vivo. Biomolecules 8: 4.

38. Van'T Hof W, Veerman ECI, Heimerhorst EJ, Nieuw Amerongen AV (2001) Antimicrobial peptides: Properties and applicability. Biological Chemistry 382: 597619.

39. Yeaman MR (2003) Mechanisms of antimicrobial peptide action and resistance. Pharmacol Rev 55: 27-55.

40. Huang Y, Huang J, Chen Y (2010) Alpha-helical cationic antimicrobial peptides: Relationships of structure and function. Protein Cell 1: 143-152.

41. Wang S, Zeng X, Yang Q, Qiao S (2016) Antimicrobial peptides as potential alternatives to antibiotics in food animal industry. International Journal of Molecular Sciences 17: 5 . 
42. GuangShun W (2014) Human antimicrobial peptides and proteins. Pharmaceuticals 7: 545-594.

43. Bechinger B, Gorr SU (2017) Antimicrobial peptides: Mechanisms of action and resistance. $J$ Dent Res 96: 254-260. [Crossref]

44. Shah P, Hsiao FSH, Ho YH, Chen CS (2016) The proteome targets of intracellular targeting antimicrobial peptides. Proteomics 16: 1225-1237.

45. Zhang LJ, Gallo RL (2016) Antimicrobial peptides. Curr Biol 26: R14-19. [Crossref]

46. Kumar P, Kizhakkedathu JN, Straus SK (2018) Antimicrobial peptides: Diversity, mechanism of action and strategies to improve the activity and biocompatibility in vivo. Biomolecules 8 .

47. Brogden KA (2005) Antimicrobial peptides: Pore formers or metabolic inhibitors in bacteria? Nature Reviews Microbiology 3: 238-250.

48. Le CF, Fang CM, Sekaran SD (2017) Intracellular targeting mechanisms by antimicrobial peptides. Antimicrobial Agents and Chemotherapy 61.

49. Mihajlovic M, Lazaridis T (2010) Antimicrobial peptides in toroidal and cylindrical pores. Biochim Biophys Acta-Biomembr 1798: 1485-1493.

50. Bertelsen K, Dorosz J, Hansen SK, Nielsen NC, Vosegaard T (2012) Mechanisms of peptide-induced pore formation in lipid bilayers investigated by oriented 31P solidstate NMR spectroscopy. PLoS One 7: e47745.

51. Swithenbank L, Morgan C (2017) The role of antimicrobial peptides in lung cancer therapy. J Antimicrob Agents 3: 1212-2472.

52. Dosler S (2017) Antimicrobial peptides: Coming to the end of antibiotic era, the most promising agents. Istanbul J Pharm 47: 72-76.

53. Wang L, Dong C, Li X, Han W, Su X (2017) Anticancer potential of bioactive peptides from animal sources (Review). Oncology Reports 38: 637-651.

54. Goodwin D, Simerska P, Toth I (2012) Peptides as therapeutics with enhanced bioactivity. Curr Med Chem 19: 4451-4461. [Crossref]

55. Fosgerau K, Hoffmann T (2015) Peptide therapeutics: Current status and future directions. Drug Discovery Today 20: 122-128.

56. Yang X, Yousef AE (2018) Antimicrobial peptides produced by Brevibacillus s: structure, classification and bioactivity: a mini review. World J Microbiol Biotechnol 34: 57.

57. Vlieghe P, Lisowski V, Martinez J, Khrestchatisky M (2010) Synthetic therapeutic peptides: science and market. Drug Discov Today 15: 40-56.

58. García JL (2018) Ingeniería genética y biotecnología. Monografia de la Real Academia Nacional de Farmacia, Madrid, Spain.

59. Gómez DM (2016) Diseño y síntesis de un péptido con y sin restricción conformacional de una proteína expresada por el Gen Pb-1 DE Oryza sativa involucrada en el mecanismo de defensa contra la pyricularia. Repos Univ Dist.

60. Ramos A, Desgarennes C (2007) Péptidos antimicrobianos: antibióticos naturales de la piel. Dermatología Rev Mex 51: 57-67.

61. Marcinkiewicz M, Majewski S (2016) The role of antimicrobial peptides in chronic inflammatory skin diseases. Postepy Dermatologii i Alergologii 33: 6-12.
62. Zhang LJ, Gallo RL (2016) Antimicrobial peptides. Curr Biol 26: R14-19. [Crossref]

63. Borovaya A, Dombrowski Y, Zwicker S, Olisova O, Ruzicka T, et al. (2014) Isotretinoin therapy changes the expression of antimicrobial peptides in acne vulgaris Arch Dermatol Res 306: 689-700.

64. Zeth K, Sancho-Vaello E (2017) The human antimicrobial peptides dermcidin and LL37 show novel distinct pathways in membrane interactions. Frontiers in Chemistry 5 : 86.

65. Wang G, Mishra B, Lau K, Lushnikova T, Golla R, et al. (2015) Antimicrobial peptides in 2014. Pharmaceuticals (Basel) 8: 123-150. [Crossref]

66. Lim HS, Chun SM, Soung MG, Kim J, Kim SJ (2015) Antimicrobial efficacy of granulysin-derived synthetic peptides in acne vulgaris. Int J Dermatol 54: 853-862.

67. McInturff JE, Wang SJ, Machleidt T, Lin TR, Oren A, et al. (2005) Granulysinderived peptides demonstrate antimicrobial and anti-inflammatory effects against propionibacterium acnes. $J$ Invest Dermatol 125: 256-263.

68. Zhang Z, Mu L, Tang J, Duan Z, Wang F, et al. (2013) A small peptide with therapeutic potential for inflammatory acne vulgaris. PLoS One 8: e72923.

69. Han R, Blencke HM, Cheng H, Li C (2018) The antimicrobial effect of CEN1HC-Br against Propionibacterium acnes and its therapeutic and anti-inflammatory effects on acne vulgaris. Peptides 99: 36-43.

70. Pollak MN, Schernhammer ES, Hankinson SE (2004) Insulin-like growth factors and neoplasia. Nat Rev Cancer 4: 505-518. [Crossref]

71. Trojan A, Aristizabal B, Jay LM, Castillo T, Penagos P, et al. (2016) Testing of IGF-I biomarker in an ethical context. Adv Modern Onco Res 2: 1-26.

72. Trojan J, Johnson T, Rudin S, Ilan J, Tykocinski M, et al. (1993) Treatment and prevention of rat glioblastoma by immugenic C6 cells expressing antisense insulin-like growth factor I RNA. Science 259: 94-97.

73. Quintero G, Gomez D, Kasprzak H, Penagos P, Siachoque H, et al. (2019) Glioblastoma - application of gene therapy during a quarter of a century: anti IGF-I strategy. Acta Sci Cancer Biol. in press: Accepted 20.11.2019.

74. Danby FW (2009) Acne, dairy and cancer: The 5alpha-P link. Dermatoendocrinol 1 12-16. [Crossref]

75. Zhang M, Qureshi AA, Fortner RT, Hankinson SE, Wei Q, et al. (2015) Teenage acne and cancer risk in U.S. women: A prospective cohort study. Cancer 121: 1682-1687.

76. Murphy JD, Sandler D, White AJ, O'Brien KM (2019) Severe acne and risk of breast cancer. Breast Cancer Res Treat 177: 487-495. [Crossref]

77. Cappel M, Mauger D, Thiboutot D (2005) Correlation between serum levels of insulinlike growth factor 1, dehydroepiandrosterone sulfate, and dihydrotestosterone and acne lesion counts in adult women. Arch Dermatol 141: 333-338.

78. Melnik BC, Schmitz G (2009) Role of insulin, insulin-like growth factor-1, hyperglycaemic food and milk consumption in the pathogenesis of acne vulgaris. Exp Dermatol 18: 833-841. [Crossref]

79. Iftikhar U, Choudhry N, Asghar A, Bashir B, Ahmad FJ, et al. (2017) Correlation of insulin-like growth factor with acne severity. APMC 11: 328-332.

80. Behrangi E, Rasi A, Navid P, Dalvand B, Azizian Z (2018) Serum level of insulin-like growth factor 1 in patients with acne vulgaris versus healthy subjects. J Skin Stem Cell 5: e79784.

Copyright: (C2019 Gómez DM. This is an open-access article distributed under the terms of the Creative Commons Attribution License, which permits unrestricted use, distribution, and reproduction in any medium, provided the original author and source are credited. 